availed myself of the first opportunity (the meeting of the Medical Institution alluded to by Dr. Imlach) to tender my resignation, stating publicly to the members the grounds of that step. I should wish to add that I highly approve of the report of the Inquiry Committee, which, I consider, takes a very moderate view of the objections to the operation in question. I remain, dear Sir, yours faithfully, J. CAMLraron, M.D., \&c.

The President, Hospital for Wqmen, Shaw-street.

P.S. - $[$ am sending a copy of this letter to THE LANCET.

\section{ARE SMALL-POX AND COW-POX ONE AND THE SAME DISEASE?}

To the Editor of THE LANCET.

SIR,-In reply to Mr. Fleming's query, I would remind him of the following points:-The physical characters of the microbes both of small-pox and vaccinia are identical, if we neglect difference of size. In both diseases the micrococci tend to arrange themselves in groups of four, and in the early stages the Malpighian mucosus is the site selected for the development of each. Pincus's description of the microscopical changes in vaccinia corresponds closely with that by Weigert of the early development of the small-pox pustule. Localisation in vaccinia probably results from the local nature of the inoculating process, the irritated parts offering the most eligible sites for exhaustion of the local manifestations. If these were excised within forty-eight hours of inoculation a more generalised exanthem would show itself (Chaureau). Infection in variola is general, not local. Constitutional symptoms consequently precede the rash. The process is centrifugal. In vaccinia the process is centripetal, and general symptoms, when present, come late. When variola is inoculated the same thing happens, but then the infective prucess is sufficiently vigorous to induce secondary general infection and a disseminated eruption. Mr. Fleming can scarcely question the identity of cowpox and vaccinia. He, however, dislikes the term "attenuation," though he will scarcely deny that Pasteur and Toussaint have independently proved the possibility of attenuating the virus of charbon by the aid of altered temperature, or that they have fixed the attenuation thus obtained, so constituting of it a generic character. If this be possible with other microbes, why not with that of variola? Man's temperature is about $37^{\circ} 5^{\circ} \mathrm{C}:{ }^{\circ}{ }^{\circ} \mathrm{C}$ higher in the horse, and as much higher still in the cow. These conditions, judging from analogy, are those favourable to attenuation. Virus from horse-pox or from cow-pox induces in man a characteristic eruption; the former sometimes causing marked constitutional symptoms with stray vesicles; the latter is less active, and seldom develops to so great an extent. But, after passing through the cow, horse virus loses its excessive activity, and acquires the name of cowpox, which, when used for inoculating man, causes no general symptoms. Repeated inoculations of cow-pox on other cows tend to fix the character of the virus-corresponding thus to the fixed attenuations of charbon virus mentioned above. In plants, modifications corresponding to such attenuations are possible. Why not with microbes? Many authors have deemed it right to affirm that variola, horse-pox, and cow-pox are not only interchangeable, but that infection with one of them is necessary to the production of the disease itself in the others. May we not go a step further, and suggest that the same cause-a specific virus floating in the atmosphere-may account for all of them, any differences being satisfactorily explained by variations of soil and temperature? In this way so-called "spontaneous cow-p $x$ " would be easily accounted for; the protective power of any one disease as against infection with the others would be more easy to understand, and it would be unnecessary to say, with Mr. Fleming, "that small-pox and cow-pox were different and antagonistic diseases." Though man may as yet have been unable to accomplish the artificial transmutation of small-pox into cow-pox, nature has methods with which we are unacquainted, but whose results Jenner's great discovery has enabled medical science to utilise. If Mr. Fleming will refer to Warlomont's Manual of Animal Vaccination, he will find more extensive reference to the subject than your columns can admit from,

Pall Mall East, S.W., Dec. 1886. Yours obedientiy ArThUR HARRIEs.

\section{DEATH OF A NIECE OF HARVEY.} To the Editor of THE LaNCET.

SIR,-In the obituary column of to-day's newspapers is recorded an event which is suggestive of interest to our profession. "On the 1st inst. at Upp Hall, Braughing, Mrs. Towers, in the ninety-eighth year of her age, the last surviving daughter of the late Admiral Sir Eliab Harvey, of Rolls Park, Essex." In the press and hurry of our day's work, the notice is likely enough to pass unheeded; but that it refers to the last of the seventh generation in direct descent from that prosperous city merchant, Eliab Harvey of London and Chigwell-park, brother of the discoverer of the circulation of the blood, should be enough to claim a moment's attention from anyone who has the slightest reverence for the past. From time to time, outside our special professional life, the public interest is awakemed by the overthrow of some fresh pretender to the rightful glory of the immortal physiologist and physician, by the erection of a statue in his native place, by the reverent re-entombment of his remains, or by the publication in facsimile of the note-book in which he himself recorded his observations and his labours. But gratifying as these events may be, they lack the living breathing kinship that the above simple announcement awakens. The deceased lady was the last of nine children of Admiral Sir Eliab Harvey and Lady Louisa, daughter of Earl Nugent. Her three brothers died childless in their father's lifetime, and, in that line at least, with her the name of Harvey ends. How the gallant old admiral, who for forty years fought the battles of his country, and ended by commanding the Téméraire at Trafalgar, is duly set forth on the marble tablet in Hempstead Church, where he sleeps with fifty of his kindred. His birth in 1758 takes us back a century ago, and those who are curious in such matters may fill in the steps 'twixt, him and his first namesake, if they consult the pedigree of the Harvey family as set forth in Wilson's History of $\mathbb{S}$. Laurence Pountney, London, 1831, at page 228, and the coffin inscriptions in the Harvey vault, lately published in the Miscellanea Genealogica et Heraldica, vol. i., series 2.

I am, Sir, yours faithfully, W. 肖. ALLCHIN.

Chandos-street, Cavendish-square, W., Dec. 4 th, 1886.

\section{A "NEW" METHOD OF EXCISING THE KNEE-JOINT. \\ To the Editor of The LaNCET.}

Sin,--I see by your report that at the Nedical Society on Monday night Mr. Herbert Allingham described as such the metinod of making a long vertical incision and dividing the patella into two lateral halves. I have twice within the last three or four years shown such a case at the West London Medico-Chirurgical Society, and the method was not new then. Anyone who will refer to my "Index of Surgery," third edition, p. 128, will see it briefly noticed there. I believe the priority of performance of this operation is due to Professor Ollier, and I am certainly of his opinion that it ought to be reserved for cases of injury to the knee-joint. It does not, according to my experience, possess a single one of the advantages which your report states that Mr. Allingham claims for it. On the contrary, it gives comparatively limited and incommodious access to the joint, and especially to its posterior and lateral recesses. In any case which proved, when the joint was opened, to be one in which the bone was very little affected, it would still be impossible, through this perpendicular section, to erase the back of the joint properly without excising much healthy bone, and thus making the prospect of restoration of mobility practically hopeless, Compare with this the plan, originated by Volkmann and adopted by Ollier and others, of opening the joint by transverse division of the patella Surely no one who has tried both can doubt the superiority of the latter. The quadriceps is no more weakened by one than by the other. There is no ligamentous or fascial structure divided in the operation which cannot be reunited by buried sutures just as effectually as can the patella itself. On the other hand, when the case to be dealt with is one of injury, the indications are quite different, and the longitudinal incision, from its possessing, although in a small degree, the advantages common to all longitudinal incisions as com- 
pared with transverse, may be reasonably preferred, for after injury there is no tubercie to be ferreted out of corners, but simply the indication to remove just as much and just as little injured bone as will suffice, and to cleanse the joint of blood and dirt.

I remain, Sir, your obedient servant.

Dec. 1886.

C. B. KeEtLet.

\section{NOTE ON THE EXISTENCE OF IODINE IN THE FREE STATE IN A MINERAL WATER.}

\section{To the Editor of THE LANCET.}

SrR,-It has been known for many years that the water of the Woodhall Spa, near Lincoln, is exceptionally rich in bromides and iodides. In the course of an investigation recently conducted by me, I have made an observation which appears to be important. I find that there is free iodine in the water-not a mere trace of free iodine, but sufficient to impart to the water a brown colour of considerable depth of tint. The proof of the presence of the free iodine in this water is very striking. There is the formation of the blue iodide of starch when a little starch paste is simply poured into the water. Another very striking characteristic is that when the water is shaken up with onetwentieth of its volume of bisulphuret of carbon it loses its brown colour, whilst the bisulphuret of carbon assumes a pink-violet colour, owing to the solution of iodine by the bisulphuret of carbon. So far as I am aware, this is the first instance in which free iodine has been found in appreciable quantity in a natural water. For many years the Woodhall Spa has been celebrated as a valuable remedy in skin diseases. The fact that it is a solution of free iodine is interesting in this. connexion, and is well worthy of the attention of the medical profession.

Dec. 15th, 1886. I am, Sir, yours obediently, J. ALFRED WANKLYN.

\section{THE TREATMENT OF ALCOHOLISM BY STRYCHNINE.}

To the Editor of THE LANCET.

SIR,-A propos of your interesting leader on the above subject published in THE LANCET of the 16th ult., I should like to be allowed to make a few passing remarks. The treatment in question, as recommended from theoretical and clinical researches by Luton, Giacomini, Magnus Huss, and other continental savants of the medical profession, and now tried by Russian practitioners, notably by Drs. Popoff and Talvinski, was extensively experimented upon, so far back as 1869 , by Deputy Surgeon-General F. G. Joynt, who was at the time medical officer in charge of the European General Hospital, Bombay. I am not aware if any other army medical officer followed his method of treatment; but suffice it to say that the drug proved in his hands a sheet-anchor in cases of ebriositas (now termed alcoholism) and delirium tremens. I may en passant mention that Dr. Joynt's solution of strychnia was, unlike the British Pharmacopæial preparation, made with dilute nitric acid and a smaller proportion of the alkaloid, and the dose usually exhibited was twenty-four minims two or three times a day.

Aden, Nov. 25th, 1886.
A. LYON MERCADO, S.M.D.

I am, Sir, yours faithfully,

\section{ST. ANDREWS UNIVFRSITY. (From a Correspondent.)}

THe Senatus Academicus of the University of St. Andrews has presented a memorial to the Right Hon. the Secretary of State for Scotland, praying for two additional chairs for its medical faculty-viz, a chair of anatomy and a chair of botany. The St. Andrews Graduates Association are also moving in the same direction. About six weeks ago a deputation appointed by the University had an interview with the Right Hon. the Secretary of State for Scotland and the Right Hon. the Lord Advocate, urging the propriety of augmenting the medical chairs to the extent indicated, by introducing a clause or clauses to that effect into the forthcoming "Universities (Scotland) Bill." St. Andrews has always felt the necessity of increasing its teaching medical staff, and attempts have been made from time to time in this direction for very many years past. The present seems a favourable opportunity for attaining the desired end. The University is desirous of increasing its teaching staff to enable it to give two anni medici, the period of residence required for medical graduation at the Scottish universities. With two additional medical chairs, St. Andrews would not only be able to give the first two years of the medical curriculum, but it would be enabled to draw upon the Extra Academical and Hospital Schools of the United Kingdom for the last two years, an arrangement which could not fail to be very convenient to many aiming at a university medical degree. St. Andrews has now a seat at the General Council of Medical Education and Registration of the United Kingdom, and is splendidly equipped as regards the teaching of chemistry, physiology, and zoology. It has also a very fine medical library and museum, and the amenities of St. Andrews as a place of study are everywhere recognised. Of late years St. Andrews has made great strides in science teaching, and if it only succeeds, by public or private endowment, in obtaining its present quest, it may in the future become as well known for its medical teaching as it has in the past been for its divinity and arts teaching.

\section{LIVERPOOL.}

(From our own Correspondent.)

THE MEDTCAL INSTITUTION AND THE HOSPITAL INQUIRY COMMITTEF.

THE special general meeting of the members of the Medical Institution, which was held on the 3rd inst., to receive the report of the Hospital Inquiry Committee, was largely attended, there being more than a hundred gentlemen present. The President (Dr. Nevins) was in the chair. The report was read by Dr. Wm. Alexander, the secretary to the Committee, and was listened to with the deepest interest by all present, each of whom was furnished with a printed copy of the report. At its conclusion the adoption of the report and a vote of thanks to the Committee were moved by Mr. McCheane, consulting surgeon to the Lock Hospital and a former president of the institution. This was seconded by Mr. C. B. Wilson, consulting surgeon to the Lying-in Hospital, and after some discussion it was carried by a large majority. Dr. Imlach spoke at considerable length, and as some of his statements were repeated in a letter which he addressed to the President of the Hospital for Women (a copy of which appeared in THE LANCET of the 11th inst.) it appears desirable to notice some points in detail. Dr. Cameron's reason for resigning his seat on the Committee was a purely personal one. He had been called in consultation with Dr. Glynn to see Dr. Imlach when the latter was dangerously $\mathrm{ill}$, and expressed an opinion that the inquiry should not proceed; but as this did not meet with the views of the other members of the Committee he resigned his seat. Mr. Bickersteth's reason for ceasing to attend was because he found himself quite unable to devote the time which he considered necessary to so important an inquiry. The primary object of the Committee was not to prepare a scientific report for the profession, but a report on the management of the Hospital for Women to the Medical Institution. The Committee were only asked to go into the cases which were the subject of operations during the year 1885. Between the early summer and the month of October the Committee held no meeting on account of the trial of Casey $v$. Imlach. The only thing done by the Committee was to request information from medical practitioners as to cases which they had seen of patients who had come under their care before and after being patients of the hospital. This information was given quite impartially and in confidence. That it could have had any prejudice against Dr. Imlach in the trial was disproved by the jury giving a verdict in his favour, without waiting for the judge's summing up. The general opinion of the profession here is that the report is a most admirable one, being exhaustive, fair, impartial, and most moderate. Too much praise cannot be given to the members of the Committee for their prolonged and self-denying devotion to the extremely invidious duty cast upon them. 